\title{
ASPECTOS COLOIDAIS DA ADESÃO DE MICRO-ORGANISMOS
}

\author{
Emiliane Andrade Araújo, Nélio José de Andrade* Antônio Fernandes de Carvalho, Afonso Mota Ramos e Cleuber \\ Antônio de Sá Silva
}

Departamento de Tecnologia de Alimentos, Universidade Federal de Viçosa, Av. PH Rolfs, s/n, Campus Universitário, 36571-000

Viçosa - MG, Brasil

Luis Henrique Mendes da Silva

Departamento de Química, Universidade Federal de Viçosa, Av. PH Rolfs, s/n, Campus Universitário, 36571-000 Viçosa - MG, Brasil

Recebido em 17/11/09; aceito em 21/4/10; publicado na web em 1/9/10

\begin{abstract}
COLLOIDAL ASPECTS OF BACTERIAL ADHESION. The ability of bacteria to attach to surface and develop into a biofilm has been of considerable interest to food industry. Electrostatic, Lifhistz-van der Waals and Lewis acid-base forces are usually considered responsible for the interactions at the interface of the bacterial adhesion. The study of microbial adhesion thermodynamic is important because it represents the reflection of microbial surface and food processing surface physicochemical characteristics. This review examines the most important aspects involved in bacterial attachment to a surface with emphases in thermodynamics of adhesion process.
\end{abstract}

Keywords: bacterial adhesion; biofilm; microbial surface thermodynamics.

\section{INTRODUÇÃO}

A adesão bacteriana é importante em um grande número de processos tecnológicos, envolvendo desde a microbiologia médica e patológica, passando pela indústria de alimentos e engenharia de meio ambiente até a área de ciência de biomateriais. ${ }^{1}$

A adesão de micro-organismos a superfícies é um fenômeno que ocorre naturalmente em meios aquosos e depende das propriedades superficiais (tensão superficial, entalpia superficial por unidade de área, composição da superfície, etc.) das interfaces dos suportes de adesão (aço, polímeros, mármore, etc.) e das membranas dos micro-organismos. Além disso, as propriedades microbiológicas e as características do meio circundante, tais como temperatura, $\mathrm{pH}$, força iônica e disponibilidade de nutrientes, determinam, em muitos sistemas, o processo de adsorção. ${ }^{1}$

A formação de um biofilme inclui muitas etapas, mas um prérequisito é a adesão das células microbianas à superfície. Estudos recentes das propriedades de adesão de bactérias têm mostrado que, em alguns casos, as características físico-químicas da superfície da célula contribuem determinantemente no processo de adesão. ${ }^{2}$

A adesão e a formação de biofilmes microbianos podem ser indesejáveis, sob diversos aspectos, em várias áreas de aplicação. A presença do biofilme em dispositivos médicos implantados já foi descrita em lentes de contato, cateteres venosos centrais, tubos endotraqueais, dispositivos intrauterinos, válvulas cardíacas mecânicas, marcapassos, cateteres de diálise peritoneal, próteses articulares, tubos de timpanostomia, cateteres urinários e de derivação ventrículo-peritoneal. ${ }^{3}$

Na indústria de alimentos, a adesão e a formação de biofilme podem tornar o processo de cloração da água menos eficiente; ${ }^{4}$ reduzir a eficiência de transferência de energia na forma de calor em trocadores térmicos; diminuir o fluxo em tubulações; desencadear processos corrosivos e, principalmente, se tornarem fontes de contaminação microbiana. ${ }^{5}$ Sob o aspecto microbiológico, a adesão pode constituir-se de micro-organismos alteradores e/ou patogênicos, que resultam em sérios problemas de higiene, de saúde pública ou de ordem econômica. ${ }^{6}$

Por outro lado, em alguns casos, o processo de adesão ou biofilme pode ser desejável, a exemplo daqueles existentes em

*e-mail: nandrade@ufv.br biorreatores utilizados na produção de alimentos fermentados. As bactérias produtoras de ácido acético crescem, adsorvendo e agregando-se em fragmentos de madeira e convertendo diversos substratos em vinagre. Esses agregados microbianos são também usados em tratamentos aeróbios e anaeróbios de águas residuárias para a remoção de matéria orgânica e inorgânica. No processo de potabilização de água, as remoções de nitrogênio, carbono biodegradável e precursores de tri-halometanos podem ser feitas por biofilmes microbianos submersos. ${ }^{7}$

Assim, esta revisão teve por finalidade analisar o processo de adesão de micro-organismos em diferentes superfícies, focando principalmente a termodinâmica do processo de adesão.

\section{TERMODINÂMICA DE ADSORÇÃO}

Adsorção é um processo espontâneo onde um componente do sistema se concentra em maior quantidade na interface do que nas outras fases em contato. A molécula difunde para a interface devido ao excesso de energia livre de Gibbs que existe na interface e, também, em virtude de interações energeticamente favoráveis que podem ocorrer entre o sólido adsorvente e o soluto, ou interações desfavoráveis entre soluto e componentes da solução. ${ }^{8}$ A adesão e formação de biofilmes constituem um processo de adsorção. Matematicamente a quantidade de moléculas adsorvidas, $\Gamma_{\mathrm{i}}$, na interface pode ser definida como: ${ }^{9}$

$\Gamma_{i}=\frac{\left(N_{i}-N_{i}^{\alpha}-N_{i}^{\beta}\right)}{A}=\left[\int_{-\delta}^{0}\left(C_{i}(z)-C_{i}^{\alpha}(z)\right) d z+\int_{0}^{+\delta}\left(C_{t}(z)-C_{i}^{\beta}(z)\right) d z\right](1)$

Para melhor entendimento das variáveis da Equação 1, considere o esquema apresentado na Figura 1. O sistema é formado pela fase $\alpha$ de volume $V_{\alpha}$ e pela região associada com a fase $\beta$ de volume $V_{\beta}$. É definido um limite $-\delta$, onde abaixo deste a densidade volumétrica da energia livre de Gibbs da interface, $\mathrm{f}_{\text {int }}=(\delta \mathrm{G} / \delta \mathrm{V})_{\mathrm{P}, \mathrm{T}}$, é igual a $\mathrm{f}_{\alpha}$, entretanto, acima de $-\delta, \mathrm{f}_{\text {int }} \neq \mathrm{f}_{\alpha}$. Para regiões abaixo de $+\delta, \mathrm{f}_{\text {int }} \neq \mathrm{f}_{\beta}$, enquanto acima de $+\delta, \mathrm{f}_{\text {int }}=\mathrm{f}_{\beta} . N_{i}, N_{i}^{\alpha}$ e $N_{i}{ }^{\beta}$ referem-se à quantidade de substância $i$ no sistema e na fase $\alpha$ e $\beta$, respectivamente; $A$ referese à entropia do sistema; $C_{i}, C_{i}{ }^{\alpha} \mathrm{e} C_{i}{ }^{\beta}$ referem-se à concentração da 
substância $i$ no sistema, na fase $\alpha$ e na fase $\beta$, respectivamente, e $z$ refere-se à coordenada perpendicular à interface.

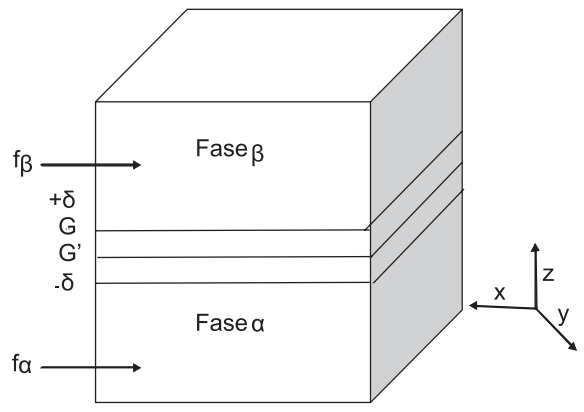

Figura 1. Representação esquemática da interface de um sistema binário

Considerando que o componente "i" não move espontaneamente para a fase $\beta$, o termo da segunda integral da Equação 1 é igual a zero e esta equação pode ser reescrita como na Equação 2:

$$
\Gamma_{i}=\left[\int_{-\delta}^{0}\left(C_{i}(z)-C_{i}^{\alpha}(z)\right) d z\right]
$$

Aplicando o teorema da integral média à Equação 2, obtêm-se a Equação 3:

$$
\Gamma_{i}=\left(C_{i}^{\mathrm{int}}-C_{i}^{\alpha}\right) \delta
$$

em que $C_{i}$ int é o valor da concentração de "i" na interface, e $C_{i}$, a concentração de "i" na fase $\alpha$.

Se $C_{i}$ int é muito maior que $C_{i}{ }^{\alpha}$, a quantidade de material adsorvido pode ser definido como na Equação 4:

$$
\Gamma_{i}=\left(C_{i}^{\text {int }}\right) \delta
$$

A quantidade de material adsorvido não é igual à concentração do componente na interface, mas sim igual à concentração do componente versus a espessura da interface.

Se a tensão interfacial de um líquido é reduzida pela adição de um soluto, este deve ter adsorvido na interface. ${ }^{10} \mathrm{~A}$ Equação 5 mostra a equação fundamental de Gibbs para o fenômeno de adsorção ocorrer em um sistema binário. ${ }^{11}$

$$
G_{T}=\gamma+\Gamma_{1} \mu_{1}
$$

em que $G_{T}$ é a variação da energia Livre de Gibbs requerida para ocorrer a adsorção, $\gamma$ é a tensão interfacial e o termo $\Gamma_{l} \mu_{1}$ refere-se à variação de energia associada ao trabalho químico de transferir soluto da solução para a interface. ${ }^{12}$

Usando a Equação 5 é possível chegar em uma equação que permite calcular a quantidade de moléculas adsorvidas em um sistema (Equações 6, 7, 8 e 9). ${ }^{9}{ }^{13}$

$$
\begin{gathered}
\frac{d G_{T}}{d \mu_{1}}=\frac{d \gamma}{d \mu_{1}}+\Gamma_{1}+\frac{d \Gamma_{1} \mu_{1}}{d \mu_{1}} \\
\frac{d G_{T}}{d \mu_{1}}=\frac{d G_{T}}{d \Gamma_{1}} \frac{d \Gamma_{1}}{d \mu_{1}}
\end{gathered}
$$

Unindo ambas as Equações 6 e 7:

$$
\frac{\mu_{1} d \Gamma_{1}}{d \mu_{1}}=\frac{d \gamma}{d \mu_{1}}+\Gamma_{1}+\frac{\mu_{1} d \Gamma_{1}}{d \mu_{1}}
$$

É possível obter:

$$
\Gamma_{1}=-\frac{d \gamma}{d \mu_{1}}
$$

em que $d \mu_{1}$ pode ser definido nas próximas equações:

$$
d \mu_{i}=d \mu^{0}+R T \ln a_{i}
$$

em que $a_{i}$ é a atividade. Expressando a Equação 10 em termos de concentração tem-se:

$$
d \mu_{i}=d \mu^{0}+R T d \ln \gamma_{1}\left[C_{1}\right]
$$

em que $\gamma_{1}$ é o coeficiente de atividade e $C_{l}$ é a concentração do soluto.

Algumas aproximações são realizadas para facilitar os cálculos, como pode ser visto nas Equações 12 e 13.

Para soluções muito diluídas:

$$
d \mu_{1}=R T d \ln \left[C_{1}\right]
$$

em que $\mathrm{C}_{1}$ é a concentração do soluto

Portanto:

$$
\Gamma_{1}=-\frac{d \gamma}{R T d \ln \left[C_{1}\right]}=-\frac{C_{1}}{R T} \frac{d \gamma}{d C_{1}}
$$

A Equação 13 é muito importante, pois permite obter a quantidade de moléculas adsorvidas $\left(\Gamma_{\mathrm{i}}\right)$ na interface por unidade de área de uma maneira mais fácil que a Equação 9. Medindo-se a tensão interfacial em função da concentração do soluto, é possível construir um gráfico de tensão interfacial versus a concentração.

\section{FORMAÇÃO DE BIOFILMES: A NATUREZA COLOIDAL DO PROCESSO DE ADESÃO}

Um sistema coloidal pode ser definido como um sistema heterogêneo, em que pelo menos uma das fases está na forma dispersa e a outra(s) fase(s) encontra(m)-se na forma contínua. Uma vez que as dimensões da fase dispersa são muito pequenas, o sistema coloidal apresenta uma área interfacial muito grande e muitas de suas propriedades termodinâmicas são influenciadas pela natureza da interface..$^{14,15}$

Devido ao tamanho da bactéria, de aproximadamente $1 \mu \mathrm{m}$, seu formato e cobertura com biomacromoléculas (Figura 2 e Tabela 1), densidade pouco superior à da água e carga global negativa, as bactérias são consideradas partículas coloidais vivas e, portanto, as propriedades físico-químicas de um sistema formado por muitas bactérias assemelham-se às dos coloides. Importantes aspectos da interação bacteriana e da adesão podem ser entendidos baseados no conhecimento das propriedades físico-químicas e coloidais da bactéria. ${ }^{16}$ As bactérias podem modificar a composição da superfície celular durante a fase de crescimento, ou em função de mudanças na composição do meio. Assim, essas alterações causam mudanças nas propriedades coloidais. ${ }^{17}$

As interações dos micro-organismos com a interface do substrato, no processo de adesão, podem ser específicas ou não específicas. Interações específicas envolvem o reconhecimento de um determinado sítio, de uma molécula receptora que se encontra na interface do micro-organismo, enquanto a interação não específica é dirigida por propriedades físico-químicas das duas interfaces interatuantes: micro-organismo e superfície na adesão. ${ }^{18}$

A combinação de dois parâmetros associados à bactéria, a hidrofobicidade celular e o potencial zeta, é considerada de relevância no 


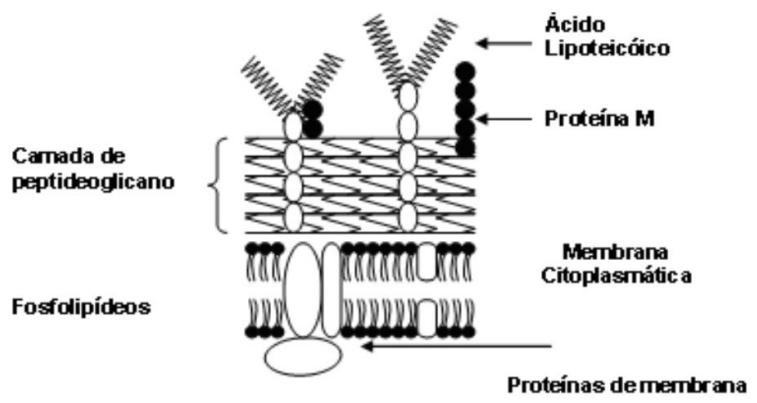

Superfície da Célula Grampositiva

(A)

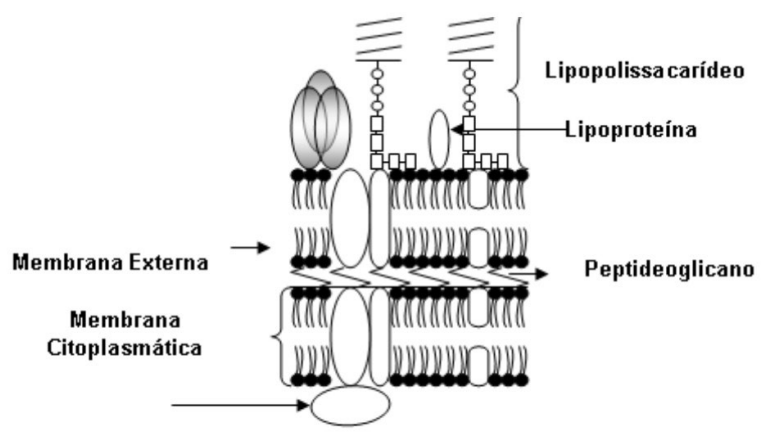

Proteínas de membrana

Superfície da Célula Gram-negativa

(B)

Figura 2. Representação esquemática de uma célula bacteriana Grampositiva (A) e uma Gram-negativa (B)

estudo das propriedades da superfície bacteriana visando o entendimento do processo de adesão não específica da bactéria ao substrato. ${ }^{18}$ Estes dois parâmetros são reflexos das inúmeras interações intermoleculares (eletrostática, covalente, de hidrogênio e de dispersão) que ocorrem entre as moléculas da interface bacteriana e da interface do substrato, sendo todas estas formas de interação fundamentais para o processo de adsorção/adesão. ${ }^{8}$

Além dos aspectos termodinâmicos, alguns fatores podem afetar o mecanismo do fenômeno de adsorção. A natureza da superfície, por exemplo, determina a área disponível para ocorrer a adsorção, e a natureza química dos compostos da interface direciona a interação que ocorre entre as moléculas e a superfície. ${ }^{19}$

Nas bactérias, essencialmente são as biomoléculas da parede celular que determinam as propriedades da superfície e, consequentemente, a termodinâmica e a dinâmica da adesão bacteriana. ${ }^{20}$

Por exemplo, as bactérias são classificadas em Gram-positivas ou Gram-negativas em função da diferença na arquitetura da parede celular. A parede celular Gram-positiva consiste de uma camada espessa de peptideoglicano $(\sim 30 \mathrm{~nm})$, enquanto a parede celular da Gram-negativa apresenta estrutura e composição da membrana mais complexa. Na Gram-negativa, a camada de peptideoglicano é mais fina $(\sim 10 \mathrm{~nm})$ e a superfície externa da célula possui uma membrana consistindo de proteínas, lipopolissacarídeos e fosfolipídeos. O espaço entre o peptideoglicano e a membrana externa é conhecido como espaço periplasmático e, em alguns pontos, é atravessado por várias enzimas e proteínas e desempenha várias funções fisiológicas (Figura 2). ${ }^{1,21}$

A superfície do peptideoglicano de bactéria Gram-positiva é coberta, principalmente, por polissacarídeos neutros e ácidos, grande número de diferentes proteínas e ácidos teicoicos..$^{22}$
Uma característica atípica da membrana externa de Gramnegativas é a distribuição assimétrica dos lipídeos sobre as faces externa e interna. A face externa contém todos os lipopolissacarídeos (LPS), enquanto a face interna contém a maioria dos fosfolipídeos. Os LPS contêm mais carga por unidade de área que os fosfolipídeos e a maioria desta carga é aniônica em $\mathrm{pH}$ neutro, devido à exposição de grupos carboxil e fosforil que podem ser ionizados. A face externa é altamente carregada e altamente interativa com cátions. ${ }^{23}$

Evidências sugerem que a presença de LPS na superfície celular de Gram-negativas tende a tornar a célula bacteriana mais hidrofílica e a perda de LPS da superfície celular torna a superfície mais hidrofóbica. Já foi relatado que a redução nos níveis de oxigênio do meio induz modificação estrutural no LPS de algumas bactérias, resultando em aumento da hidrofobicidade da célula. Isto indica que a bactéria é capaz de alterar as características da superfície celular, como a hidrofobicidade, em função das mudanças no ambiente externo. ${ }^{24}$

Os grupos carboxil e fosforil conferem à superfície celular uma densidade de carga negativa. Uma vez que a superfície celular está em contato direto com o ambiente, os grupos carregados dentro da camada da superfície são capazes de interagir com os íons ou moléculas carregadas presentes no meio externo. Como resultado, os cátions podem tornar-se atraídos eletrostaticamente e ligarem-se na superfície celular. ${ }^{25}$ Os locais responsáveis pela ligação de metais no micro-organismo são provavelmente nestes grupos carboxil dentro do peptideoglicano, assim como nos grupos fosforil de ácidos teicoicos e teicurônicos presentes nas superfícies bacterianas. ${ }^{26}$

A carga da superfície bacteriana varia de acordo com a espécie e é influenciada pelas características do meio de crescimento, como $\mathrm{pH}$ e força iônica, idade da bactéria e estrutura da superfície. O nível de dissociação de grupos carboxil, amino e fosfato na parede celular não é somente determinado pelo $\mathrm{pH}$, mas também pela concentração da solução eletrolítica. ${ }^{27}$ A magnitude das interações eletrostáticas diminui com aumento da força iônica devido à blindagem das cargas da superfície. As interações eletrostáticas perdem sua influência quando há forte força iônica.

Algumas outras classes de componentes biomoleculares podem estar presentes na superfície bacteriana. Os exopolissacarídeos são polissacarídeos secretados pelas bactérias e considerados componentes determinantes das propriedades físico-químicas de biofilmes, consistindo não somente de polissacarídeos, mas também de quantidades consideráveis de proteína, ácido nucleico e lipídeos. Os EPS estão envolvidos na formação de agregados microbianos e oferecem estabilidade ao biofilme. Entretanto, esses processos não são mediados pela formação de ligações covalentes C-C entre moléculas EPS, mas sim por interações intermoleculares físico-químicas fracas. Três tipos de interações não covalentes têm sido considerados: forças de dispersão de London, interações eletrostáticas e ligações de hidrogênio. ${ }^{28}$

A superfície celular bacteriana exerce importante função no estágio inicial de adesão das células. As condições de crescimento afetam o sistema de síntese da parede que, por sua vez, afetam os polímeros aniônicos e as enzimas presentes na parede do micro-organismo. Características da superfície dependem do $\mathrm{pH}$ da cultura e do estado energizado da membrana. Mudanças nas propriedades de superfície induzidas por diferentes valores de $\mathrm{pH}$ do ambiente de crescimento podem explicar aumento na adesão à superfície.

A adesão de diferentes estirpes de bactérias é também influenciada pelas propriedades físico-químicas e termodinâmicas do substrato envolvido, baseado nas análises das características da superfície em termos de carga elétrica e hidrofobicidade. ${ }^{29}$

As superfícies mais comumente utilizadas na indústria de alimentos são as dos substratos aço inoxidável e as de polímeros, em função de suas excelentes propriedades e baixo custo em relação aos demais 
Tabela 1. Estrutura química de diferentes componentes da superfície celular microbiana

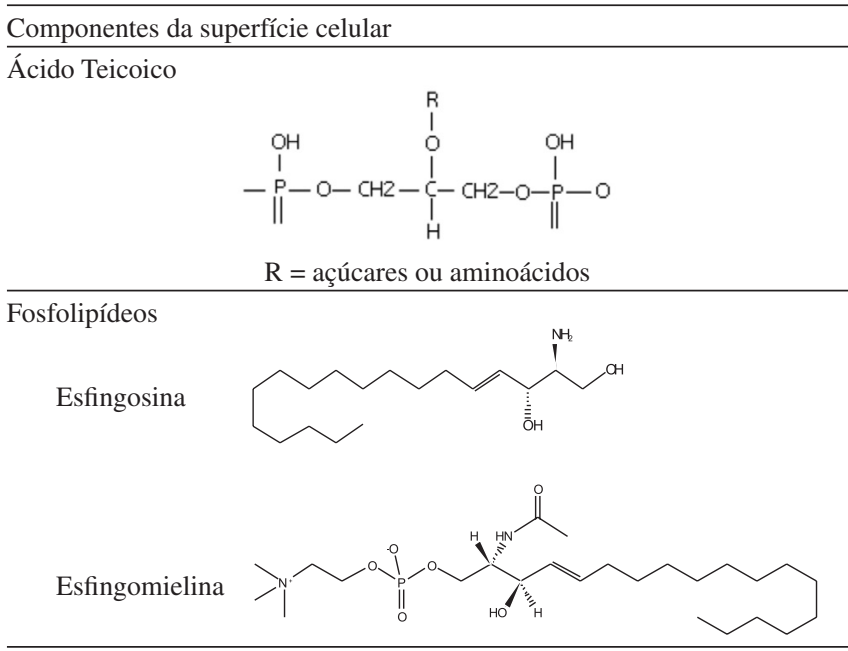

Peptideoglicano
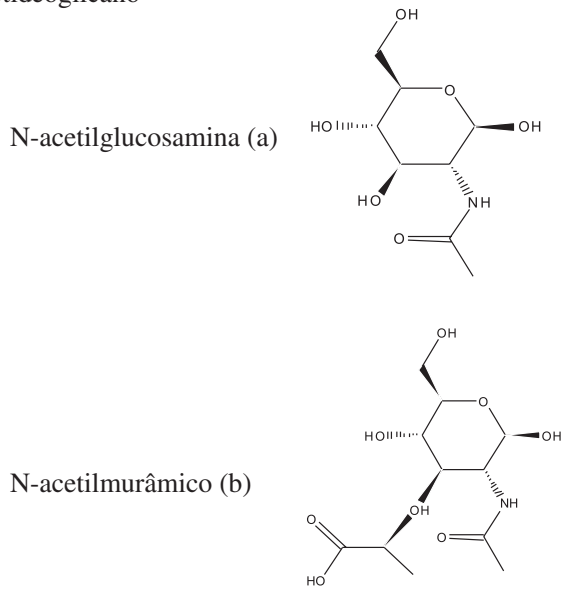

Lipopolissacarídeo

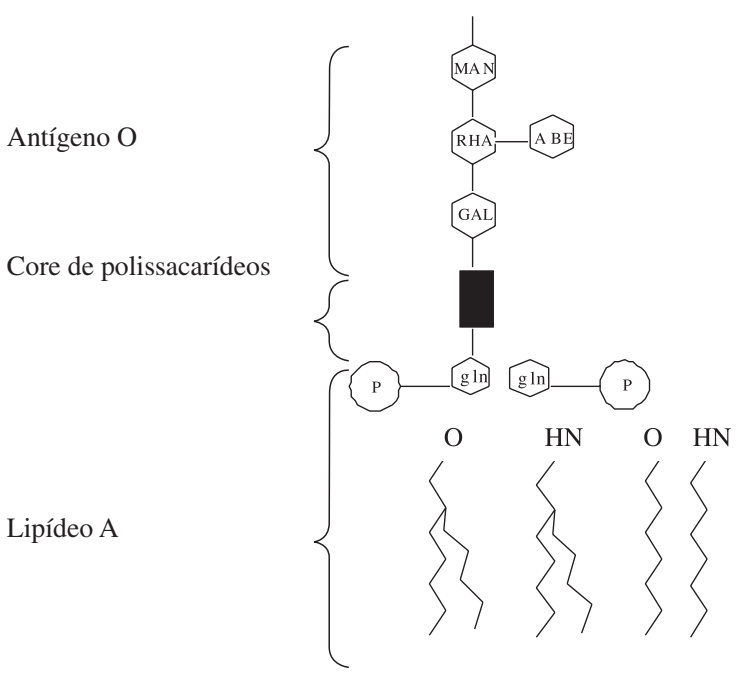

materiais. São geralmente empregadas na fabricação de tanques, tubulações, acessórios e em superfícies de processamento de alimentos.

O aço inoxidável pode ser produzido em vários graus de polimento, dependendo da finalidade, o que afeta a adesão bacteriana devido a suas várias microtopografias e propriedades físico-químicas. ${ }^{30} \mathrm{~A}$ principal diferença entre os graus de aço disponíveis comercialmente é sua composição relativa de ferro, cromo e níquel e a baixa porcentagem de carbono. Dentre os vários tipos de aços inoxidáveis disponíveis, os mais utilizados são os do chamado grupo 18 - 8, ou seja, que apresentam em sua composição aproximadamente $18 \%$ de cromo e $8 \%$ de níquel. Deste grupo, as alterações do grau 300, por exemplo, 304 e 316, satisfazem à maioria das necessidades da indústria de alimentos. O grau 304 é resistente à corrosão originada pela maioria dos alimentos e agentes de limpeza. Em problemas de corrosão mais intensos deve ser empregado o grau 316 que apresenta cerca de $10 \%$ de níquel e $3 \%$ de molibdênio. O aço inoxidável difere também no acabamento da superfície, que pode variar de acordo com o polimento empregado que se classifica de 1 , sem polimento, até 8 , cuja superfície é espelhada. Normalmente, a indústria de alimentos utiliza o aço inoxidável 304 com polimento $4 .^{31,32}$

O teor de molibdênio é a principal diferença na composição do aço inoxidável e é capaz de afetar a natureza da camada de passivação presente na superfície do aço inoxidável. A camada de passivação consiste de uma mistura de óxidos de ferro, cromo e molibdênio e apresenta participação no processo de adesão de bactérias. ${ }^{33}$

Em relação aos polímeros comumente utilizados na indústria de alimentos, suas propriedades variam bastante, dependendo da matériaprima utilizada, dos aditivos incorporados e do método de fabricação. Basicamente, são agrupados em duas categorias: termoplásticos e termoestáveis. Os termoplásticos mais comumente encontrados em indústrias de alimentos são: polietileno, polipropileno, poli (cloreto de vinila) ou PVC e acrílico, entre outros. No grupo dos termoestáveis estão o poliéster, resinas epóxi e poliuretanos, polímeros usados na fabricação de equipamentos envolvidos no processamento de alimentos. ${ }^{34}$

Os substratos sólidos apresentam características físicas e químicas heterogêneas. Essa heterogeneidade é devida à complexidade da estrutura cristalina dos sólidos e de sua composição química variada. ${ }^{29}$ A adsorção de espécies diferentes ou de grupos distintos carregados na superfície também pode contribuir para a heterogeneidade da superfície ${ }^{35}$ Essas superfícies heterogêneas produzem locais altamente favoráveis para adesão bacteriana.

As superfícies de processamento de alimentos adquirem carga elétrica superficial no meio aquoso, devido à ionização dos grupos químicos presentes na superfície ou por meio de adsorção de íons na interface. ${ }^{27}$

Quando a bactéria se aproxima da superfície do substrato, ocorre o início do desenvolvimento de interações resultantes da atmosfera iônica, que circunda as duas superfícies. A intensidade dessa força depende do potencial elétrico das duas superfícies, da força iônica e constante dielétrica do meio circundante e, ainda, da distância entre a bactéria e o substrato. ${ }^{36}$

A presença de íons de ferro na superfície provoca modificações nas interações eletrostáticas entre a superfície sólida e as células microbianas. Estes íons carregados positivamente reduzem as interações repulsivas eletrostáticas entre a célula microbiana e a superfície sólida, carregadas negativamente, conduzindo a um aumento na adesão bacteriana em um líquido com baixa força iônica. ${ }^{37}$

Um fator também contribuinte para potencializar os efeitos físicoquímicos na adesão é a característica topográfica da superfície. Tem sido hipotetizado que a bactéria adere em superfícies rugosas por três razões: maior área disponível para adesão, proteção das forças de cisalhamento e trocas químicas que causam interações físicoquímicas preferenciais. ${ }^{38}$

A microtopografia da superfície pode aumentar ou diminuir a associação da bactéria à superfície. Superfícies que entram em contato com alimentos apresentam diferentes microtopografias de superfície e podem conter fissuras e fendas com tamanho suficiente para alojar bactérias. ${ }^{39} \mathrm{O}$ aumento dos níveis de adesão associados à rugosidade da superfície é atribuído à proteção das células no interior das irregularidades da superfície, permitindo que a adesão irreversível seja 
estabelecida mais facilmente, sendo, por isso, locais preferenciais para a colonização inicial. ${ }^{40}$

$\mathrm{Na}$ literatura, as opiniões variam em relação ao efeito das características da superfície na adesão bacteriana. Alguns pesquisadores relatam que há uma correlação positiva entre adesão e aumento da rugosidade, enquanto outros pesquisadores não reportam nenhuma correlação entre a habilidade da bactéria aderir e irregularidades ou rugosidade das superfícies. Este aparente conflito está relacionado com o nível de rugosidade estudada, com as espécies bacterianas estudadas, os parâmetros físico-químicos da superfície e o método usado para detectar a bactéria na superfície. ${ }^{33}$

\section{INTERAÇÕES INTERMOLECULARES}

\section{Interações eletrostáticas}

No mundo microscópico dos coloides e interfaces, a presença ou ausência de cargas superficiais pode ter grande significância em termos de estabilidade, sensibilidade ao ambiente, propriedades eletrocinéticas e outros fatores. A interação entre dois átomos carregados ou moléculas é potencialmente a forma mais forte de interação física a ser considerada na interface e no sistema coloidal.

A superfície bacteriana pode adquirir cargas por diferentes mecanismos, tais como ionização de grupos de átomos presentes na superfície, adsorção preferencial de íons e solubilização preferencial de moléculas presentes na interface do micro-organismo. ${ }^{41}$ Estes mecanismos são geralmente dependentes das propriedades da solução aquosa, principalmente do seu $\mathrm{pH}$. A interface de uma bactéria carregada eletricamente, juntamente com os íons existentes no líquido próximo à interface, e que estão sob a influência do campo de força causado pelas moléculas da superfície do micro-organismo, formam uma camada difusa de íons chamada dupla camada elétrica (Figura 3).

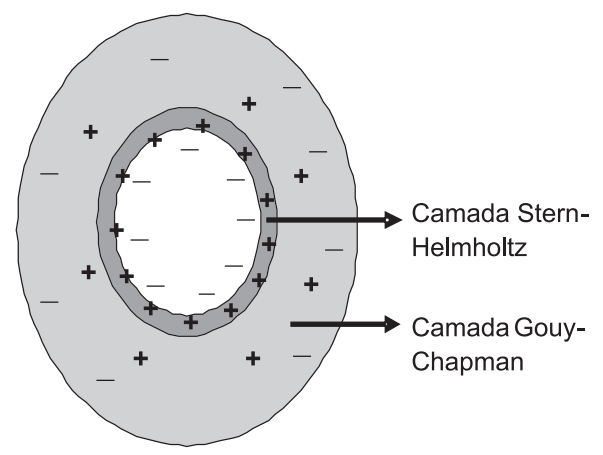

Figura 3. Representação esquemática da dupla camada elétrica da superficie celular

A ideia da dupla camada elétrica foi primeiramente proposta por Helmholtz, que desenvolveu o conceito de um sistema tendo cargas organizadas em dois planos paralelos. Entretanto, sabe-se que o modelo é inadequado, uma vez que esta distribuição paralela e organizada não existe. Na realidade, o movimento térmico de íons na solução introduz certo nível de caos acarretando o espalhamento dos íons na região de superfície carregada, formando a dupla camada difusa. ${ }^{42}$

A distribuição de íons ao redor da interface objetiva reduzir a energia livre de Gibbs do sistema. Quando o equilíbrio termodinâmico é alcançado, o potencial eletroquímico de cada espécie iônica é mantido constante, como pode ser observado na Equação $14:^{43}$

$\overline{\mu_{i}}=\mu_{i}+z_{i} e \varphi(x) N_{A}=\mu_{i}^{o}+R T \ln n_{i}+z_{i} e \varphi(x) N_{A}=$ Const

em que $\bar{\mu}_{i}$ é o potencial eletroquímico $\mathrm{Z}_{\mathrm{i}}$ se refere à carga do íon, $e$ é carga do elétron, $\varphi(\mathrm{x})$ é a diferença no potencial elétrico entre a interface e um ponto $\mathrm{P}$ localizado numa certa distância " $\mathrm{x}$ " perpendicular à interface; $\mu_{\mathrm{I}}$ é o potencial químico, $\mathrm{n}_{\mathrm{i}}$ é a quantidade de ions por $\mathrm{m}^{3}$, $\mathrm{N}_{\mathrm{A}}$ é a constante de Avogadro, R é a constante dos gases e T a temperatura em Kelvin.

A Equação 14 mostra que há três principais fatores que coordenam a configuração do íon ao redor da interface. O primeiro, $\left(\bar{\mu}_{i}^{0}\right)$, é a energia de interação entre íons e moléculas presentes na interface. O segundo, (RT $\ln n_{\mathrm{i}}$ ), é a contribuição do trabalho químico no posicionamento dos íons ao redor da interface e está associado com a entropia configuracional dos íons, determinado principalmente pelo movimento térmico das espécies carregadas. E, o terceiro $\left(\mathrm{Z}_{\mathrm{i}} \mathrm{e} \varphi(\mathrm{x}) \mathrm{N}_{\mathrm{A}}\right)$ refere-se à energia devida às interações eletrostáticas ocorrendo entre um íon com carga $\mathrm{Z}$ e a atmosfera iônica que gera o potencial elétrico $\varphi(\mathrm{x})$.

As interações intermolecular $\left(\bar{\mu}_{i}^{o}\right)$ e eletrostática $\left(\mathrm{Z}_{\mathrm{i}} \mathrm{e} \varphi(\mathrm{x}) \mathrm{N}_{\mathrm{A}}\right)$ irão determinar, principalmente, a organização de íons em uma camada densa, formada por espécies químicas não solvatadas. Esta camada está próxima à interface e é conhecida como camada Stern-Helmholtz. Mais distante da interface, é formada uma camada difusa, denominada de camada Gouy-Chapman, onde a distribuição do íon depende da entropia (RT ln $n_{i}$ ) e de interações eletrostáticas (Figura 3). ${ }^{11}$

A lei fundamental que rege as interações entre espécies carregadas é a Lei de Coulomb. A interação entre duas cargas $q_{1}$ e $q_{2}$ no vácuo $\left(\mathrm{F}_{\mathrm{el}}\right)$ separadas por uma distância $\mathrm{r}$, segue a Equação 15:44

$$
F_{e l}=\frac{q_{1} q_{2}}{4 \pi \varepsilon_{0} \varepsilon r^{2}}
$$

em que $\varepsilon_{0}$ representa a permeabilidade do vácuo.

O trabalho necessário para trazer as duas cargas juntas de infinito para uma distância $r$ é: 45

$$
w(r)=-\int_{\infty}^{r} F_{e l} d r=\frac{q_{1} q_{2}}{\left(4 \pi \varepsilon_{0} \varepsilon r\right)}
$$

Para cargas de mesmo sinal, $w(r)$ será positivo e a interação será repulsiva; se a carga for oposta, a interação será atrativa.

Se a carga $\mathrm{q}_{l}$ for isolada no espaço, ela produzirá um campo elétrico em um ponto $r$, tal que o trabalho necessário para trazer uma unidade de carga elétrica do infinito a uma distância $r$ de q será igual:

$$
w(r)=\frac{q_{1}}{\left(4 \pi \varepsilon_{0} \varepsilon r\right)}
$$

A quantidade de trabalho é definida como potencial elétrico $(\psi)$ na distância $r$ devido à carga $\mathrm{q}_{1}$.

Para aplicar a Lei de Coulomb para soluções de eletrólitos e coloides, é necessário empregar a Lei de distribuição de Boltzmann, que relata a probabilidade de uma unidade de átomo, molécula, íon ou partícula estar a certo ponto com uma energia livre específica, relativa a um estado de referência específico. A probabilidade é geralmente expressa em termos de uma concentração média, $c$, no ponto $r$ relativo a uma concentração, $c_{0}$, na mesma distância referência que a energia é tomada como zero. Na temperatura, $T$, a distribuição de Boltzmann é dada como: ${ }^{42}$

$$
c=c_{0} \exp \frac{-\Delta G}{K T}
$$

A Equação 19 prediz que se existe potencial elétrico negativo, $\psi$, em algum ponto na solução eletrolítica, então na região daquele ponto a concentração de cargas positivas, $c+$, pode ser dada por:

$$
c+=c_{0} \exp \frac{-z^{+} e \psi}{K T}
$$


em que $z^{+}$é a valência do íon positivo e $c_{0}$ é a concentração do íon positivo na região onde $\psi=0$. Uma expressão similar pode ser escrita para íons negativos na solução:

$$
c-=c_{0} \exp \frac{+z^{-} e \psi}{K T}
$$

Embora a solução como um todo seja eletricamente neutra, na vizinhança do potencial elétrico existe um desequilíbrio de cargas elétricas. Portanto, para um $\psi$ negativo, haverá mais íons positivos na região que íons negativos. Para o caso, em que $z^{-}=z^{+}=1$, o excesso é dado por:

$$
c_{+}-c_{-}=c_{0}\left[\exp \left(\frac{-e \psi}{K T}\right)-\exp \left(\frac{+e \psi}{K T}\right)\right]
$$

O potencial eletrocinético ou potencial zeta de macromoléculas, partículas, ou superfícies é a diferença de potencial em um meio uniforme entre um ponto a uma distância da superfície e um ponto no plano de cisalhamento e é medido por métodos eletrocinéticos, tais como eletroforese, diferença de potencial osmótico e diferença de potencial de sedimentação. ${ }^{46}$

O potencial zeta é importante nos estudos de química de superfície, visto que pode ser usado para prever e controlar a estabilidade de sistemas coloidais. O potencial zeta de célula bacteriana é, em geral, negativo e uniforme na superfície celular, uma vez que a carga na parede bacteriana é homogênea. ${ }^{24} \mathrm{Em}$ geral, o potencial zeta de bactérias varia de -10 a $-90 \mathrm{mV}$.

Uma correlação entre carga da superfície e adesão não é fácil. A dificuldade está nas características da superfície celular, que varia entre as espécies bacterianas. Em geral, há heterogeneidade nas superfícies celulares, em que muitos componentes podem diferir entre as espécies.

\section{Interação Lifshitz-van der Waals (LW)}

As forças de van der Waals governam as interações envolvendo uma variedade de moléculas e são responsáveis pela estabilidade de complexos intermoleculares e adsorção de diferentes elementos na superfície.

Durante a adesão microbiana, além da interação eletrostática, existem três principais tipos de forças agindo entre átomos e moléculas em níveis moleculares. Essas forças são comumente denominadas de van der Waals. Dentre as três, duas envolvem dipolos induzidos e permanentes, e a terceira é considerada a força mais fundamental e universal, sendo a mais importante contribuição da interação total de van der Waals. ${ }^{47}$ Esta força é a chamada London-van der Waals, primeiramente postulada por van der Waals em 1873 e depois explicada por London em $1930 .{ }^{48}$ Deste modo, a interação de van der Waals entre átomos e moléculas podem ser de três tipos: dipolo-dipolo, dipolo-dipolo induzido e interação de London.

As forças indutoras ocorrem na interação entre uma molécula com momento de dipolo permanente e uma molécula não polar. O campo elétrico da molécula dipolar distorce a distribuição de carga elétrica da outra molécula, produzindo um momento de dipolo induzido dentro da molécula. A energia resultante desta interação é chamada de segunda ordem. Esta contribuição está simultaneamente presente com a contribuição eletrostática no caso da interação de duas moléculas polares. ${ }^{49}$

As forças dispersivas ocorrem entre duas moléculas que não possuem momentos de dipolos permanentes. Embora a molécula não possua momento de dipolo permanente, seus elétrons estão em constante movimento com sua densidade oscilando continuamente no tempo e espaço. Deste modo, em qualquer instante, qualquer molécula possui um dipolo elétrico instantâneo que flutua como a densidade eletrônica flutua. O dipolo instantâneo numa molécula induz um dipolo instantâneo numa segunda molécula. O dipolo induzido na segunda molécula interage com o dipolo induzido na primeira para produzir uma energia atrativa chamada de energia de dispersão. A energia de dispersão é o resultado de correlações entre flutuações da densidade de elétrons nas duas moléculas. ${ }^{50}$

\section{Interação ácido-base de Lewis (AB)}

Além das interações de van der Waals e das interações eletrostáticas, verificou-se a existência de outras forças de interação que também podem ter um papel importante na interação entre coloides. Estas forças de interação apresentam um caráter polar e podem ser atrativas ou repulsivas. ${ }^{2}$ As interações ácido-base constituem o balanço das interações que são responsáveis pela tensão interfacial. As interações do tipo $\mathrm{AB}$ ocorrem entre as moléculas que estão muito próximas. $\mathrm{Na}$ água e, provavelmente, em outros líquidos polares, as interações podem ser induzidas por mudanças na orientação das moléculas do líquido. ${ }^{51}$

Em meios aquosos, as forças de interação polares devem-se principalmente a interações entre doadores e receptores de elétrons que representam interações do tipo ácido-base de Lewis, que são geralmente designadas por $\mathrm{AB} .^{52}$

As interações interfaciais são relevantes para a definição de hidrofobicidade e hidrofilicidade. A diferença básica entre hidrofobicidade e hidrofilicidade é a competição entre a energia livre interfacial de coesão do sólido, imerso na água, e a energia livre de coesão do líquido. ${ }^{53}$

A tendência das moléculas de água de evitar interações desfavoráveis com solutos apolares constitui uma força dirigida para a agregação destes solutos. Cada molécula de água é fortemente inclinada a não sacrificar nenhuma de suas ligações de hidrogênio, conduzindo a uma reorientação significante das moléculas de água na superfície da molécula do soluto não polar. Ocorre uma mudança na intensidade de energia das moléculas de água na superfície do soluto. As ligações de hidrogênio são quebradas quando as moléculas de água estão em contato com o ar ou superfícies apolares. ${ }^{54}$

A importância do caráter hidrofóbico da superfície das células na adesão é explicada pelo estabelecimento de uma adesão efetiva entre duas superfícies em meio aquoso, o filme de água que as separa tem que ser removido e a hidrofobicidade das superfícies interatuantes contribui para a facilidade dessa remoção. Portanto, a interface bactéria/líquido e a interface superfície de adesão/líquido terão que ser substituídas pela interface bactéria/superfície de adesão. Segundo a teoria termodinâmica, a adesão só se verifica se o processo conduzir a uma redução da energia livre global. ${ }^{55}$

O parâmetro $\Delta \mathrm{G}^{\text {tot }}$ expressa a variação da energia livre associada à atração polar entre as moléculas das duas superfícies. Quando a energia livre de interação é repulsiva, isto é, o $\Delta \mathrm{G}^{\text {tot }}$ é positivo, as superfícies são ditas hidrofílicas. Quanto mais negativo o valor de $\Delta \mathrm{G}^{\text {tot }}$ mais hidrofóbicas são as superfícies, por outro lado, quanto mais positivo o valor de $\Delta \mathrm{G}^{\text {tot }}$ mais hidrofílica é a superfície. ${ }^{56}$

A energia livre da interação interfacial entre as moléculas do material imersos na água é a mais apropriada medida da hidrofobicidade. A tensão interfacial é determinada pelo somatório entre a componente apolar e polar da respectiva superfície (Equação 22) ${ }^{52}$

$$
\gamma_{l}(1+\cos \theta)=2 \sqrt{\gamma_{s}^{L W} \gamma_{l}^{L W}}+2 \sqrt{\gamma_{s}^{-} \gamma_{l}^{+}}+2 \sqrt{\gamma_{s}^{+} \gamma_{l}^{-}}
$$

em que $\gamma_{L}$ é a tensão superficial total do líquido; $\gamma_{L}^{L W}$ e $\gamma_{S}^{L W}$ são as tensões superficiais das forças de interação Lifshitz-van der Waals; $\gamma_{L}{ }^{+}$e $\gamma_{S}{ }^{+}$são as componentes aceptoras de elétrons do componente ácido-base da tensão superficial; e $\gamma_{S}^{-}$e $\gamma_{S}^{-}$são as componentes doadoras de elétrons do componente ácido-base da tensão superficial, 
considerando-se que são as tensões para os líquidos $(l)$ e para a superfície $(s)$ analisados.

Existem relatos demonstrando que $\gamma^{-}$é sempre maior do que $\gamma^{-}$em superfícies bacterianas de E. coli, P. fluorescens, B. subtillis e P. aerugino$s a$. Isto comprova a teoria de que as células têm caráter doador de elétrons $(\gamma$-) predominante. Todas as biossuperfícies são predominantemente doadoras de elétrons como consequência da presença do oxigênio na atmosfera da Terra e da hidratação da superfície da célula microbiana. ${ }^{20}$

Somente o ângulo e a $\gamma_{L}$ podem ser determinadas experimentalmente. Os termos restantes são estimados baseados em considerações teóricas que são divididas em dois grupos: teoria macroscópica e microscópica. Na teoria macroscópica, o equilíbrio do ângulo de contato entre o líquido diagnosticado e a superfície é determinado pela tensão total da superfície de sólidos e líquidos $\gamma_{s l}$ Já a teoria microscópica, considera a natureza química do líquido, uma vez que as contribuições de diferentes tipos de interações intermoleculares na energia livre de uma superfície são determinadas individualmente. ${ }^{57}$

Os três modelos principais para a conversão de valores de ângulos de contato em parâmetros físico-químicos da superfície são: a equação de estado (ES), a média geométrica (GME) e a Lifshitz-van der Waals ácido-base (LWAB). Os modelos ES e GME têm sido criticados por suposições equivocadas em relação à natureza das interações interfaciais. Deste modo, a abordagem LWAB é a mais indicada, pois proporciona informações detalhadas da química da superfície, sendo capaz de determinar valores para os componentes ácido e base em adição aos componentes de dispersão da energia livre da superfície..$^{58,59}$

Para converter os valores de ângulos de contato em parâmetros físico-químicos da superfície é preciso determinar as três componentes da tensão interfacial $\left(\gamma_{L}^{L W}, \gamma_{s}^{+} \mathrm{e} \gamma_{s}^{-}\right)$das superfícies. Essa determinação é feita por meio do ângulo de contato formado por três líquidos de polaridades diferentes cujos componentes da tensão interfacial são conhecidos (Tabela 2). Os componentes da tensão interfacial são obtidos após resolver simultaneamente as três equações obtidas quando valores dos ângulos de contato formados sobre a superfície são substituídos na Equação 22.

Tabela 2. Componentes das tensões interfaciais das substâncias a $25^{\circ} \mathrm{C}$

\begin{tabular}{lcccc}
\hline Substâncias & \multicolumn{4}{c}{ Tensão Interfacial $\left(\mathrm{mJ} / \mathrm{m}^{2}\right)$} \\
& $\gamma_{l}^{\text {tot }}$ & $\gamma_{l}^{L W}$ & $\gamma_{l}^{+}$ & $\gamma_{i}$ \\
\hline$\alpha$-bromonaftaleno & 44.4 & 44.4 & 0.0 & 0.0 \\
Água & 72.8 & 21.8 & 25.5 & 25.5 \\
Formamida & 58.0 & 39.0 & 2.28 & 39.6 \\
\hline
\end{tabular}

A medida do ângulo de contato é o método mais exato para determinar a energia de interação entre um líquido (L) e um sólido (S) a uma distância de equilíbrio mínima $\left(l_{0}\right)$ entre $\mathrm{S}$ e L. O cosseno (cos) do ângulo de contato é a medida do equilíbrio entre as energias de coesão entre as moléculas do líquido $\left(\gamma_{1}\right)$ e as forças de adesão entre líquido e sólido, expressa como $\Delta \mathrm{G}_{S L}$. Ângulos de contato são obtidos somente quando a energia de coesão do líquido é maior que a energia de adesão entre líquido e sólido. ${ }^{48}$

A energia livre de interação hidrofóbica $\Delta \mathrm{G}_{\mathrm{sws}}{ }^{\text {TOT }}$ entre as moléculas da superfície (s) imersa em água (w) é calculada pelo somatório das componentes apolar e polar da energia livre de interação, $\Delta \mathrm{G}_{\mathrm{sws}}{ }_{\mathrm{LW}}$ e $\Delta \mathrm{G}_{\mathrm{sws}}{ }^{\mathrm{AB}}$, respectivamente. ${ }^{60}$

$$
\Delta G_{s w s}^{t o t}=\Delta G_{s w s}^{L W}+\Delta G_{s w s}^{A B}
$$

Aplicando as Equações 24 e 25, é possível chegar ao valor de

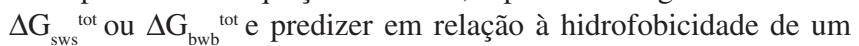
substrato $(s)$ ou de uma superfície celular $(b)$ :

$$
\begin{gathered}
\Delta G_{s w s}^{L W}=-2 \sqrt{\gamma_{s}^{L W}-\gamma_{w}^{L W}} \\
\Delta G_{s w s}^{A B}=-4\left(\sqrt{\gamma_{s}^{+} \gamma_{s}^{-}}+\sqrt{\gamma_{w}^{+} \gamma_{w}^{-}}-\sqrt{\gamma_{s}^{+} \gamma_{w}^{-}}-\sqrt{\gamma_{w}^{+} \gamma_{s}^{-}}\right)
\end{gathered}
$$

A partir dos valores das componentes da tensão interfacial é possível determinar a $\Delta \mathrm{G}_{\text {ades̃o }}$ entre as duas superfícies: célula microbiana (b) e superfícies de processamento (s):

$$
\begin{gathered}
\gamma_{b s}=\gamma_{b s}^{L W}+\gamma_{b s}^{A B} \\
\gamma_{b s}^{L W}=\gamma_{b}^{L W}+\gamma_{s}^{L W}-2 \sqrt{\gamma_{b}^{L W} \gamma_{s}^{L W}} \\
\gamma_{b s}^{A B}=2\left(\sqrt{\gamma_{b}^{+} \gamma_{b}^{-}}+\sqrt{\gamma_{s}^{+}} \gamma_{s}^{-}-\sqrt{\gamma_{b}^{+} \gamma_{s}^{-}}-\sqrt{\gamma_{b}^{-}} \gamma_{s}^{+}\right)
\end{gathered}
$$

em que $\gamma_{\mathrm{bs}}$ é a tensão interfacial entre as superfícies bactéria/superfície de adesão; $\gamma_{\mathrm{bs}}{ }^{\mathrm{LW}}$ é a componente apolar, interação de Lifshitz-van der Waals entre bactéria e superfície; $\gamma_{\mathrm{s}}^{\mathrm{AB}}$ é a componente polar (interação de ácido-base de Lewis) entre bactéria e superfície.

As mesmas equações $(26,27$ e 28$)$ devem ser empregadas no cálculo da tensão interfacial entre as superfícies bactéria/líquido $\left(\gamma_{\mathrm{bl}}\right)$ e tensão interfacial entre a superfície de adesão/líquido $\gamma_{\mathrm{sl}}$.

Como a energia livre está diretamente relacionada à tensão interfacial, $\Delta \mathrm{G}_{\text {adesão }}$ pode ser representado da seguinte forma:

$$
\begin{gathered}
\Delta G_{\text {adesão }}=\Delta G_{b l s}^{L W}+\Delta G_{b l s}^{A B} \\
\Delta G_{b l s}^{L W}=\gamma_{b s}^{L W}-\gamma_{b l}^{L W}-\gamma_{s l}^{L W} \\
\Delta G_{b l s}^{A B}=\gamma_{b s}^{A B}-\gamma_{b l}^{A B}-\gamma_{s l}^{A B}
\end{gathered}
$$

$\mathrm{O}$ valor de $\Delta \mathrm{G}_{\text {adesão }}$ permite fazer uma avaliação termodinâmica do processo de adesão, sendo esta termodinamicamente favorável quando $\Delta \mathrm{G}_{\text {adesão }}<0$ e, ao contrário, desfavorável quando $\Delta \mathrm{G}_{\text {adesão }}>0$.

\section{Teoria do processo de adesão celular}

A adesão de micro-organismos a superfícies pode ser interpretada de acordo com a teoria geral de estabilidade de coloides, conhecida como teoria DLVO, por combinação das iniciais dos autores Derjaguin e Landau, Verwey e Overbeek. ${ }^{61}$ A clássica teoria DLVO parte da definição de que os micro-organismos seriam partículas quimicamente inertes, ${ }^{62}$ ou seja, seriam como coloides liofóbicos. Essa teoria afirma que a energia potencial total de interação entre dois corpos é resultante da ação combinada entre as forças atrativas de Lifshitzvan der Waals e as forças de dupla camada elétrica, que geralmente são repulsivas, uma vez que a maioria das superfícies adquire carga negativa em solução.

A contribuição das interações consideradas pela teoria DLVO resulta num perfil de energia potencial que é muito dependente da força iônica do meio. Assim, se a força iônica do meio é baixa, o perfil de energia potencial de interação entre os dois corpos de sinal igual apresenta um máximo de energia, que representa uma barreira para a aproximação dos corpos, e um mínimo de energia, designado mínimo primário, que se localiza a uma distância inferior a $2 \mathrm{~nm}$ da superfície. Quando se aumenta a força iônica do meio, a barreira de energia diminui, devido à redução da energia da dupla camada elétrica. Assim, para valores intermédios da força iônica do meio, o máximo de energia diminui e cria-se um mínimo secundário. Este, quando os micro-organismos interatuantes são bactérias, situa-se a 5-20 nm da superfície. Uma vez ultrapassado o máximo de energia e atingido o mínimo primário, a ligação entre os dois corpos interatuantes torna-se irreversível. Para valores elevados da força iônica do meio, a energia potencial de interação é sempre negativa e neste caso todas as partícu- 
las podem atingir o mínimo primário. A existência de dois mínimos de energia permite distinguir entre a adesão reversível e irreversível. ${ }^{2}$

A teoria DLVO explica a adesão de micro-organismos com base na interação entre partículas coloidais. Além disso, as forças de interação contabilizadas por esta teoria são apenas as forças de longo alcance (forças de van der Waals e forças resultantes da dupla camada elétrica). Deste modo, esta teoria só permite prever se os micro-organismos se aproximam a certa distância da superfície, não permitindo quantificar a energia potencial dessa interação. Quando uma partícula atinge o mínimo primário, um conjunto de forças de curto alcance passa a dominar a interação e a determinar as forças de adesão. ${ }^{47,63}$

A teoria DLVO estendida surgiu para complementar a teoria DVLO e adiciona à teoria clássica forças ácido-base de Lewis, para considerar os aspectos relacionados aos micro-organismos no processo de adesão. Assim, a energia livre das interações totais numa superfície é resultante do somatório das energias livres das interações de Lifshitz-van der Waals, interações ácido-base de Lewis e forças eletrostáticas de dupla camada elétrica. ${ }^{64,65}$

\section{Aplicações da teoria termodinâmica no processo de adesão}

A hidrofobicidade de diferentes espécies de bactérias, representativas dos principais gêneros, isoladas de uma ordenhadeira mecânica foi estudada assim como a hidrofobicidade dos seguintes materiais: borracha, aço inoxidável (SS) 316 e (SS) 304, vidro e polimetilmetacrilato. A determinação da hidrofobicidade da superfície foi obtida pela medida do ângulo de contato de três líquidos de polaridades diferentes com os cupons $(3,0 \times 2,0 \mathrm{~cm})$ de cada material avaliado. Os valores dos ângulos de contatos medidos, com auxílio de um aparelho goniômetro, foram adicionados nas equações anteriormente demonstradas e, por meio dos valores dos componentes de tensão das superfícies, foi obtida a energia livre de interação $\left(\Delta \mathrm{G}_{\mathrm{iww}}\right)$ entre duas moléculas do material (i) quando imersos em água (w). Quando a interação entre duas entidades foi maior que a interação de cada entidade com a água, o material foi considerado hidrofóbico. O mesmo procedimento foi adotado para células bacterianas, sendo o ângulo de contato formado sobre uma camada de células depositadas em uma membrana após processo de filtração de um concentrado de células. Em relação à hidrofobicidade das bactérias, todas as estirpes de Lactobacillus lactis lactis bem como de Enterococcus faecalis foram consideradas hidrofóbicas. As estirpes de Pseudomonas aeruginosa e Staphylococcus sciuri tiveram valores variados para a hidrofobicidade, tendo estirpes da mesma espécie classificada como hidrofóbicas, enquanto outras foram hidrofílicas (Tabela 3). Todos os materiais avaliados foram hidrofóbicos, sendo a borracha, aço inoxidável SS 316 e SS 304 as superfícies mais hidrofóbicas e o vidro a superfície mais hidrofílica. A energia livre de adesão entre a bactéria e os materiais em meio aquoso foi calculada a fim de predizer qual superfície possui maior habilidade para a formação de biofilmes. Para todas as situações estudadas, a adesão foi termodinamicamente favorável ao aço inoxidável SS 316, SS 304 e à borracha e menos favorável nas superfícies de polimetilmetacrilato e vidro. ${ }^{66}$

A implantação dos íons $\mathrm{N}^{+}, \mathrm{O}^{+}, \mathrm{SiF}_{3}^{+}$na superfície do aço inoxidável 316 foi investigada, uma vez que os íons implantados tornam a superfície menos atrativa para a bactéria afetando o processo de adesão. Uma das razões é que a implantação do íon reduz a energia livre da superfície, influencia a molhabilidade e diminui a rugosidade da superfície. Neste estudo, a dose e a energia de implantação dos íons foram de $10^{16}$ íns $/ \mathrm{cm}^{2}$ e $30 \mathrm{KeV}$, respectivamente. Todas as superfícies avaliadas apresentaram-se lisas e com morfologia uniforme. A rugosidade das superfícies $\mathrm{R}_{\mathrm{a}}$ para os íons implantados $\mathrm{N}^{+}$, $\mathrm{O}^{+}, \mathrm{SiF}_{3}{ }^{+}$foi 200,129 e 36 angstrons, respectivamente. Com relação à energia da superfície, não houve diferença óbvia no componente
Tabela 3. Energia livre $\left(\mathrm{mJ} / \mathrm{m}^{2}\right)$ de interação entre micro-organismos (i) imersos em água (w) e de diferentes materiais (i) imersos em água (w)

\begin{tabular}{lc}
\hline Micro-organismos ou materiais & $\Delta \mathrm{G}_{\mathrm{iwi}}$ \\
\hline Pseudomonas aeruginosa 1 & 6,1 \\
Pseudomonas aeruginosa 4 & $-60,7$ \\
Pseudomonas aeruginosa 6 & 19,6 \\
Pseudomonas aeruginosa 14 & $-27,9$ \\
Pseudomonas aeruginosa 63 & 84,7 \\
Lactobacillus lactis lactis 8 & $-24,6$ \\
Lactobacillus lactis lactis 62 & $-12,9$ \\
Lactobacillus lactis lactis 73 & $-18,7$ \\
Staphylococcus sciuri 45 & $-13,3$ \\
Staphylococcus sciuriI 50 & $-27,5$ \\
Staphylococcus sciuri 55 & 12,5 \\
Staphylococcus sciuri 60 & 13,9 \\
Enterococcus faecalis 70 & $-21,9$ \\
Enterococcus faecalis 76 & $-24,4$ \\
Enterococcus faecalis 77 & $-12,7$ \\
Borracha & $-57,8$ \\
SS 316 & $-58,1$ \\
SS 304 & $-54,4$ \\
Vidro & $-14,8$ \\
Polimetilmetacrilato & $-18,9$ \\
\hline
\end{tabular}

apolar da superfície, entretanto, o componente polar para $\mathrm{SiF}_{3}{ }^{+}$foi o menor componente entre as superfícies avaliadas. Como resultado, a energia total da superfície de aço inoxidável com $\mathrm{SiF}_{3}{ }^{+}$implantado foi a menor $(48,30 \mathrm{mN} / \mathrm{m})$, enquanto para os outros sistemas foi 56,10 para $\mathrm{N}^{+}$implantado e $54,23 \mathrm{mN} / \mathrm{m}$ para $\mathrm{O}^{+}$implantado. Os autores também observaram que a superfície com a presença do íon $\mathrm{SiF}_{3}{ }^{+}$ apresentou a melhor redução da adesão bacteriana. Neste estudo, a adesão bacteriana reduziu com a diminuição da energia da superfície. As superfícies com íons implantados apresentaram melhores resultados que as superfícies controle, quanto à adesão. Os autores concluíram que a superfície de aço inoxidável com $\mathrm{SiF}_{3}{ }^{+}$pode exercer importante função na redução de células aderidas. ${ }^{67}$

A influência das propriedades físico-químicas da superfície na adesão de Pseudomonas aeruginosa foi estudada em polímeros moderadamente hidrofóbicos e em superfícies hidrofílicas obtidas por irradiação de $50 \mathrm{keV} \mathrm{Ar}^{+}$e por tratamento de plasma- $\mathrm{O}_{2}$. Os polímeros utilizados no tratamento foram poli-hidroximetilsiloxano (PHMS) e polietilenotereftalato (PET). O PET foi utilizado, pois seu caráter hidrofóbico não é afetado após aplicação de ambos os tratamentos. Os autores observaram rápida produção de exopolissacarídeos nas superfícies de alta polaridade e formação de estrutura de multicamadas complexas após $2 \mathrm{~h}$ de incubação. As modificações químicas induzidas pela irradiação mudaram drasticamente a energia livre das superfícies. A superfície PHMS antes do tratamento apresentava alta hidrofobicidade, em virtude da orientação dos grupos metil na superfície. Esta superfície tornou-se moderadamente hidrofílica após a irradiação e muita hidrofílica após tratamento com plasma. Por outro lado, a molhabilidade do PET não teve mudanças significativas após a irradiação e aumentou levemente após o tratamento com plasma. Em ambos os tratamentos para PHMS, a energia livre da superfície aumentou. Este efeito é devido ao aumento das forças dispersivas Lifshitz-van der Waals e polar de Lewis. No caso da superfície de PET, as modificações da energia livre foram menos pronunciadas, no entanto os componentes dispersivos e polares tiveram pequenas variações. Quanto às medidas de rugosidade, não houve diferença significativa após os tratamentos, com exceção da superfície PHMS tratada com plasma. ${ }^{68}$

\section{CONCLUSÃO}

O fenômeno da adesão bacteriana depende de interações físicoquímicas que ocorrem entre a superfície celular e um substrato. A 
estabilidade de um biofilme bacteriano é obtida por meio de interações Lifshitz-van der Waals, eletrostáticas e ácido-base de Lewis. As características das duas superfícies interatuantes, tais como a hidrofobicidade, carga elétrica e condições ambientais, influenciam o processo de adesão e consequente formação do biofilme.

$\mathrm{O}$ entendimento da termodinâmica da adesão microbiana é importante, uma vez que possibilita predizer se a adesão de uma determinada bactéria é favorável ou não em diferentes superfícies. Com o conhecimento dos parâmetros físico-químicos da superfície é possível desenvolver novas estratégias, que tornem a superfície menos atrativa para os micro-organismos.

\section{AGRADECIMENTOS}

Ao apoio financeiro dos órgãos CNPq e FAPEMIG.

\section{REFERÊNCIAS}

1. Ubbink, J.; Schar-zammaretti, P.; Curr. Opin. Colloid Interface Sci. 2007, 12, 263.

2. Chaves, L. C. D.; Dissertação de Mestrado, Universidade do Minho, Portugal, 2004.

3. Azeredo, J.; Oliveira, R.; Biofouling 2000, 16, 59.

4. Donlan, R. M.; Emerging Inf. Dis. 2001, 7, 277.

5. Masaaki, M.; J. Biosci. Bioeng. 2006, 101, 1.

6. Beech, I. B.; Int. Biodet. Biodeg. 2004, 53, 177.

7. Andrade, N. J.; Higiene na indústria de alimentos, Varela: São Paulo, 2007.

8. Somasundaran, P.; Markovic, B.; Yu, X.; Krishnakumar, S. Em Handbook of Surface and Colloid Chemistry; Birdi, K. S.; ed.; CRC Press: Lincoln, 2003.

9. Pires, A. C. S.; Silva, M. C. H.; Silva, L. H. M. Em Engineering Aspects of Milk and Dairy Products; Coimbra, J. S. dos R., ed.; CRC Press Taylor \& Francis Group: New York, 2009, cap. 1.

10. Prpich, A. M.; Biswas, M. E.; Chen, P.; J. Phys. Chem. C 2008, 112, 2522.

11. Fadrique, J. C.; Langmuir 2002, 18, 3604.

12. Adamson, A. W.; Alice, P.; Physical Chemistry of Surfaces, $6^{\text {th }}$ ed., John Wiley and Sons, Inc: New York, 1997.

13. Goodwuin, J. W.; Colloids and Interfaces with Surfactants and polymers - an Introduction, John Wiley and Sons, Inc: Chichester, 2004.

14. Norde, W.; Colloids and Interfaces in Life Sciences, Marcel Dekker, Inc: New York, 2003.

15. Vicent, B. Em Colloid Science: Principles, Methods and Applications; Cosgrove, T.; ed.; Blackwell Publishing: Ames, 2005.

16. Dufrêne, Y. F.; Curr. Opin. Microbiol. 2003, 6, 317.

17. Schar-zammaretti, P.; Ubbink, J.; Biophys. J. 2003, 85, 4076.

18. Abbasnezhad, H.; Gray, M. R.; Foght, J. M.; Colloids Surf., B 2008, 62, 36.

19. Das, S. K.; BhowaL, J.; Das, A. R.; Guha, A. K.; Langmuir 2006, 22, 7265 .

20. Strevett, K. A.; Chen, G.; Res. Microbiol. 2003, 154, 329.

21. Beveridge, T.; J. Bacteriol. 1999, 181, 4725.

22. Jefferson, K. K.; FEMS Microbiol. Lett. 2004, 236, 163.

23. Camesano, T.; Abu-Lail, N.; Environ. Sci. Technol. 2003, 37, 2173.

24. Palmer, J.; Flint, S.; Brooks, J.; J. Ind. Microbiol. Biotechnol. 2007, 34, 577.

25. Langley, S.; Beveridge, T. J.; Appl. Environ. Microbiol. 1999, 65, 489.

26. Katsikogianni, M.; Missirlis, Y. F.; Eur. Cells Mater. 2004, 8, 37.

27. Hong, Y.; Brown, D. G.; Langmuir 2008, 24, 5003.

28. Flemming, H. C.; Wingender, J.; Griebe, T.; Mayer, C. Em Recent Advances in their study and control; Evans, L. V.; ed.; British Library: Amsterdam, 2005.

29. Vadillo-Rodriguez, V.; Logan, B.; Environ. Sci. Technol. 2006, 40, 2983.
30. Jullien, C.; Bénézech, T.; Carpentier, B.; Lebret, V.; Faille, C.; J. Food. Engin. 2002, 56, 77.

31. Whitehead, K. A.; Verran, J.; Int. Biodet. Biodeg. 2007, 60, 74.

32. Nosei, L.; Farina, S.; Ávalos, M.; Náchez, L.; Gómez, B. J.; Feugeas, J.; Thin Solid Films 2008, 516, 1044.

33. Flint, S. H.; Brooks, J. D.; Bremer, P. J.; J. Food. Engin. 2000, 43, 235.

34. Rodolfo Jr.; Nunes, L. R.; Ormanji, W.; Tecnologia do PVC, Proeditores/ Braskem: São Paulo, 2002.

35. Taboada-Serrano, P.; Vithayaveroj, V.; Yacoumi, S.; Tsouris, C.; Environ. Sci. Technol. 2005, 39, 6352.

36. Sheng, X.; Ting, Y. P.; Pehkonen, S. O.; J. Colloid Interface Sci. 2008, $321,256$.

37. Li, B.; Logan, B.E.; Colloids Surf., B 2004, 36, 81.

38. Scheuerman, T. R.; Camper, A. K.; Hamilton, M. A.; J. Colloid Interface Sci. 1998, 208, 23.

39. Arnold, J. W.; Bailey, G. W.; Pollut. Sci. 2000, 79, 1839.

40. Verran, J.; Whitehead, K. A.; Food Bioprod. Proc. 2006, 84, 260.

41. Riley, J. Em Colloid Science: Principles, Methods and Applications; Cosgrove, T., ed.; Blackwell Publishing: Ames, 2005.

42. Ni, H.; Amme, R. C.; J. Colloid Interface Sci. 2003, 260, 344.

43. Lavalle, P.; Picart, C.; Mutterer, J.; Gergely, C.; Reiss, H.; Voegel, J. C.; Senger, B.; Schaaf, P.; J. Phys. Chem. B 2004, 108, 635.

44. Patra, M.; Hyvönen, M. T.; Falck, E.; Sabouri-Ghomi, M.; Vattulainen, I.; Mikko, K.; Comput. Phys. Commun. 2007, 176, 14.

45. Myers, D.; Surfaces, Interfaces, and Colloids: Principles and Applications, $2^{\text {nd }}$ ed., John Wiley \& Sons, Inc: New York, 1999.

46. Lameiras, F. S.; Souza, A. L. S.; Rodrigues, V. A. M.; Numes, E. H. M.; Braga, I. D.; Mater. Res. 2008, 11, 217.

47. Liang, Y.; Hilal, N.; Langston, P.; Starov, V.; Adv. Colloid Interface Sci. 2007, 134-135, 151.

48. van Oss, C. J.; Interfacial Forces in Aqueous Media, Marcel Dekker, Inc: New York, 1994.

49. Haibo Yu, H.; van Gunsteren, W. F.; Comput. Phys. Commun. 2005, 172, 69.

50. Lee, S.; Sigmund, W. M.; Colloids Surf., A 2002, 204, 43.

51. van Oss, C. J.; J. Mol. Recognit. 2003, 16, 177.

52. Jacobs, A.; Lafolie, F.; Herry, J. M.; Debroux, M.; Colloids Surf., B 2007, 59, 35 .

53. Meyer, E. E.; Rosenberg, K. J.; Israelachvili, J.; Proc. Natl. Acad. Sci. U. S. A. 2006, 103,15739 .

54. Blokzijl, W.; Engberts, J. B. F. N.; Angew. Chem., Int. Ed. 1993, 32, 1545 .

55. van Loosdrecht, M.; Norde, W.; Lyklema, L.; Zehnder, J.; Aquatic Sci. 1990, 52,103.

56. Bayoudh, S.; Othmane, A.; Bettaieb, F.; Bakhrouf, A.; Ouada, B.; Ponsonnet, L.; Mater. Sci. Eng., C 2006, 26, 300.

57. Scheneider, P. R.; J. Adhes. Sci. Technol. 1997, 11, 65.

58. Long, J.; Chen, P.; Langmuir 2001, 17, 2965.

59. Jurak, M.; Chibowski, M.; Adsorption 2009,15, 211.

60. van Oss, C. J.; Colloids Surf., B 2007, 54, 2.

61. Liu, Y.; Yang, C. H.; Li, J.; Environ. Sci. Technol. 2008, 42, 159.

62. van Oss, C. J.; Chaudhury, M. K.; Good, R. J.; Adv. Colloid Interface Sci. 1987, 28, 35.

63. Chen, G.; Strevett, K. A.; Environ. Microbiol. 2001, 3, 237.

64. Oliveira, K. M. P.; Tese de Doutorado, Universidade Estadual de Londrina, Brasil, 2006.

65. Sharma, P. K.; Hanumantha Rao, K.; Colloids Surf., B 2003, 29, 21.

66. Teixeira, P.; Lopes, Z.; Azeredo, J.; Oliveira, R.; Vieira, M. J.; Food Microbiology 2005, 22, 247.

67. Zhao, Q.; Liu, Y.; Wang, C.; Wang, S.; Peng, N.; Jeynes, C.; Med. Engin. Physics 2008, 30, 341.

68. Carnazza, S.; Satriano, C.; Guglielmino, S.; Marletta, G.; J. Colloid Interface Sci. 2005, 289, 386. 